\title{
Attachment in the Early Life Course: Meta-Analytic Evidence for Its Role in Socioemotional Development
}

\author{
Ashley M. Groh, ${ }^{1}$ R. M. Pasco Fearon, ${ }^{2}$ Marinus H. van IJzendoorn, ${ }^{3}$ \\ Marian J. Bakermans-Kranenburg, ${ }^{3}$ and Glenn I. Roisman ${ }^{4}$ \\ ${ }^{1}$ University of Missouri, ${ }^{2}$ University College London, ${ }^{3}$ Leiden University, and ${ }^{4}$ University of Minnesota
}

ABSTRACT_After decades of research on early attachment relationships, questions remain concerning whether the evidence supports claims made by attachment theory, in particular, that variation in early attachment predicts children's developmental adaptation or maladaptation, and that characteristics of children's temperament does not determine attachment. To evaluate these claims, we conducted meta-analyses on early attachment and children's social competence with peers, externalizing problems, internalizing symptoms, and temperament. In this article, we summarize our findings, which support attachment theory-though we note caveats. We also call for new measurement models, a focus on mediating and moderating mechanisms, and multisite replications.

KEYWORDS—attachment; meta-analysis; child adjustment

Attachment theory $(1,2)$ has been a generative theoretical framework for investigating the developmental origins and legacy of children's early experiences with parents. Attachment theory proposes that parents' sensitive caregiving, not children's endogenous characteristics, primarily determines individual differences in attachment security (3). Specifically, experiences of

Ashley M. Groh, University of Missouri; R. M. Pasco Fearon, University College London; Marinus H. van IJzendoorn, Leiden University; Marian J. Bakermans-Kranenburg, Leiden University; Glenn I. Roisman, University of Minnesota.

Marian J. Bakermans-Kranenburg and Marinus H. van IJzendoorn were supported by research awards from the Netherlands Organization for Scientific Research (Bakermans-Kranenburg, the SPINOZA prize, and van IJzendoorn, a VICI grant).

Correspondence concerning this article should be addressed to Ashley M. Groh, 204B McAlester Hall, Columbia, MO 65211; e-mail: groha@missouri.edu.

(C) 2016 The Authors

Child Development Perspectives $\odot 2016$ The Society for Research in Child Development DOI: $10.1111 /$ cdep.12213 parental (in)sensitivity are encoded by children into an internal working model encompassing views of the self, others, and the nature of relationships that influences developmental adaptation $(4,5)$. Thus, attachment theory claims that early attachment security should be largely independent of children's individual characteristics (e.g., temperament) and predicts more optimal socioemotional outcomes (including higher quality interpersonal relationships and fewer externalizing and internalizing problems).

These claims have received much attention in almost five decades of research on attachment (6-9). However, findings have not always converged, and together with the sheer size of the literature, range of correlates examined, and diversity of samples investigated, reviewers have found it difficult to draw conclusions about the significance of early attachment for socioemotional (mal)adaptation. Meta-analysis provides a structured, principled way to quantitatively summarize complex literatures, test theories, and generate new hypotheses. Accordingly, we conducted quantitative reviews examining the relation between early attachment and children's peer competence (i.e., social skills, the quality of children's interactions with peers, and social status; 10), externalizing symptoms (i.e., aggression, oppositional problems, conduct problems, and hostility; 11), internalizing symptoms (i.e., depression, anxiety, social withdrawal, and somatic complaints; 12), and temperament (i.e., negative emotional reactivity and regulation; 13).

We addressed questions about the developmental significance of early attachment security versus insecurity by quantifying the association between early attachment and adaptation within these developmental domains and comparing meta-analytic associations across developmental domains to examine whether early security has narrow or broad significance (14). We also examined the dynamic nature of these meta-analytic associations over childhood to determine whether the predictive significance of early attachment endures or diminishes over time (15), and we tested whether the effects of attachment vary by 
population (e.g., clinical status, sex, socioeconomic adversity). For each developmental domain, we examined the relative significance of patterns of insecurity, as some insecure classifications may be linked more closely to some outcomes than others. We restricted our focus to studies that began in early childhood, and we used standardized observational assessments of attachment to be reasonably confident that we were examining common studies using similar definitions and measurement frames, uncontaminated by shared method variance or informant bias. Because relatively few studies have examined attachment between children and fathers, there were either too few studies to include in the meta-analysis (11) or the few studies limited the conclusions we could draw $(10,12,13)$. In this article, we summarize findings from this work in relation to mother-child attachment, first focusing on findings for secure versus insecure infants and then on those for patterns of insecurity and disorganization. We also discuss their meaning and significance for ongoing research.

\section{THE DEVELOPMENTAL SIGNIFICANCE OF EARLY ATTACHMENT SECURITY}

\section{Sequelae and Origins of Early Attachment Security}

According to attachment theory, early security may have the strongest implications for children's peer relationships, and important yet weaker implications for psychopathology (14). By carving the literature on attachment into distinct developmental domains, our meta-analyses estimated more precisely the association between security and (mal)adaptation within these domains and allowed us to evaluate the relative significance of attachment across developmental domains. Early security was associated with greater social competence $(d=.39 ; 10)$, fewer externalizing problems $(d=.31 ; 11)$, and to a lesser extent, fewer internalizing problems $(d=.15 ; 12)$. Moreover, early security was associated most strongly with children's subsequent interactions with peers (i.e., social competence and externalizing difficulties, which often manifest in peer contexts) and weakly with internalizing symptoms (see Figure 1).

By traditional standards, the effect sizes between early security and children's peer competence and externalizing symptomatology were modest, falling between Cohen's (16) criteria for small $(d=.20)$ and medium $(d=.50)$ effects, suggesting that any simplistic notion that security determines peer interactions in childhood and aggressive behavior is likely incorrect. However, meta-analytic associations should be considered in the context of other studies examining similar phenomena and using similar methods (17). In that respect, the combined effect sizes are not trivial, as they are comparable to the meta-analytic associations between parenting and delinquency $(d=.39 ; 18)$ and parenting and relational aggression $(d=.22 ; 19)$. These meta-analytic associations gain greater significance considering that they are relatively free from measurement bias and occur

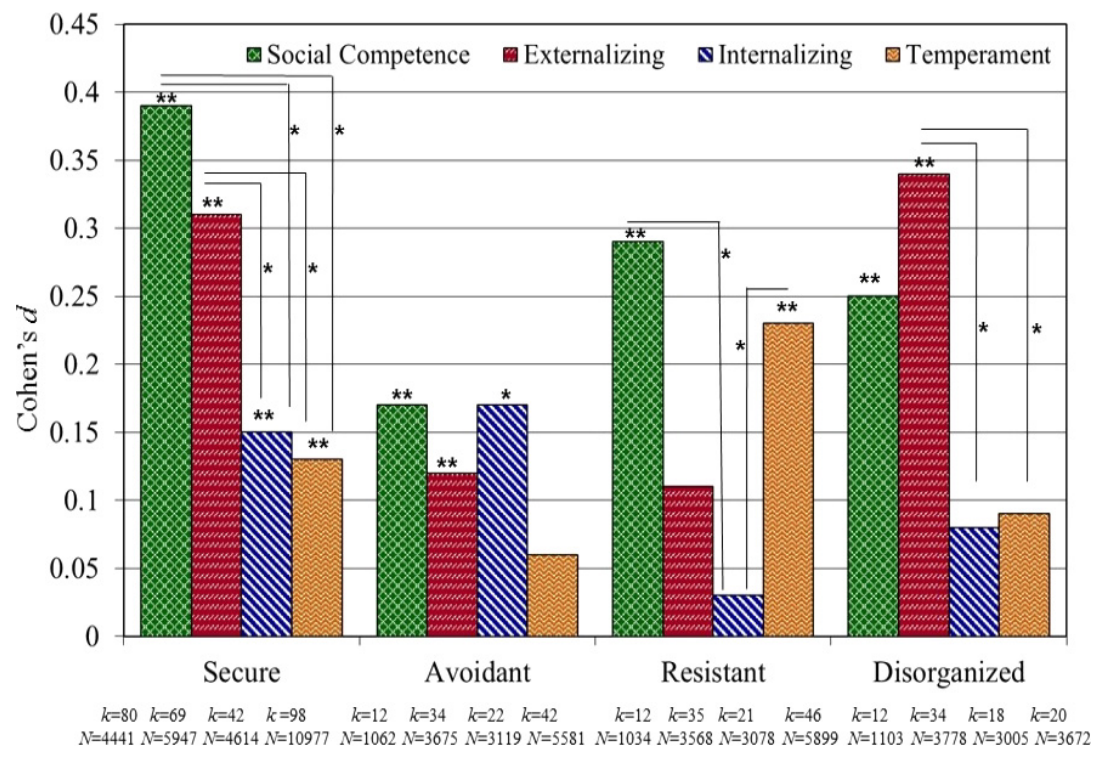

Figure 1. Combined effect sizes for the four attachment categories for social competence with peers, externalizing symptoms, internalizing symptoms, and temperament. [Color figure can be viewed at wileyonlinelibrary.com]

Note. Secure $=$ secure versus insecure; Avoidant $=$ insecure avoidant versus not avoidant; Resistant $=$ insecure resistant versus not resistant; Disorganized = disorganized versus not disorganized. Effect sizes are presented in the direction of hypotheses. Thus, security was associated meta-analytically with higher levels of social competence and lower levels of externalizing and internalizing symptomatology, whereas insecure subtypes were associated meta-analytically with lower levels of social competence and higher levels of externalizing and internalizing symptomatology. Security and avoidance were associated meta-analytically with lower levels of negative temperament, whereas resistance and disorganization were associated meta-analytically with higher levels of negative temperament. Asterisks over bars indicate significant combined effect sizes. Asterisks along lines indicate significant differences between the combined effect sizes. $N=$ total number of children; $k=$ number of independent studies. ${ }^{*} p<.05 .{ }^{* *} p<.01$. 
over lengthy periods. In contrast, the association between insecurity and internalizing problems was weak, a finding we return to later.

Regarding the origins of attachment, security is thought to be rooted in the caregiving environment and thus to have little relation to temperament (3). In our meta-analysis, attachment security was associated with lower levels of negative temperament $(d=.13 ; 13)$. However, this association was significantly weaker than that between security and social competence and externalizing (but not internalizing) problems (see Figure 1), providing little evidence that temperament determines security status.

\section{The Legacy of Attachment Security Across Childhood}

Supporting the idea that attachment has enduring significance for developmental (mal)adaptation (15), we found that associations between security and children's peer competence and internalizing symptoms did not vary according to age of outcome assessment $(10,12)$, the association between attachment and externalizing problems increased with age (11), and the temporal lag between attachment and outcome assessments did not moderate any of the meta-analytic associations. As these meta-analyses comprised children from 1 to $12-14$ years and the lag between attachment and outcome assessments ranged from 0 months to 13 years, these findings suggest that, although modest, the significance of early security for children's socioemotional adaptation does not wane from infancy to early adolescence. However, these studies cannot determine whether such stability is due to the early effects of attachment on stable psychobiological structures or continuity in caregiving, a point we return to later.

\section{Moderators of Meta-Analytic Associations With Attachment Security}

We examined whether the meta-analytic associations between early security and socioemotional adaptation were moderated by factors that have been linked with or indicate psychological problems (e.g., parent or child diagnosed with psychiatric disorder; prenatal exposure to drugs), children's sex, or socioeconomic status. The association between insecurity and externalizing symptomatology was stronger when either the child or the parent had been diagnosed with a psychiatric disorder (see Figure 2; 11). In addition, children's sex moderated the association between insecurity and externalizing problems, with a stronger association for boys (11), supporting the claim that insecurity might be linked with externalizing problems in boys but not the related assertion that insecurity might be linked to internalizing symptoms in girls (8). Socioeconomic status did not significantly moderate any of the meta-analytic associations (1012), providing little support for a diathesis-stress model in which the effect of insecurity is strongest in economically deprived populations. These findings suggest that early insecurity places boys and children from clinical populations (i.e., children or parents with psychiatric difficulties) at heightened risk for externalizing problems, but that such factors play little role in amplifying the negative impact of insecurity on peer competence and internalizing problems.

\section{THE DEVELOPMENTAL SIGNIFICANCE OF EARLY AVOIDANT, RESISTANT, AND DISORGANIZED ATTACHMENTS}

In the meta-analyses, we examined the shared and distinctive significance of early avoidant, resistant, and disorganized attachments (see Figure 1). Consistent with expectations that all patterns of insecurity might undermine social competence (7), early avoidant, resistant, and disorganized attachments were negatively associated with peer competence and the 85\% CI for the point estimates overlapped, suggesting that each pattern of insecurity was associated comparably with less peer competence (10). Regarding psychopathology, a somewhat unanticipated pattern emerged: Avoidance was significantly associated with externalizing and internalizing problems, whereas resistance was not significantly associated with either symptom domain $(11,12)$, providing little support for the claim that avoidant and resistant attachments serve as distinctive diatheses for externalizing versus internalizing problems, respectively (20). Moreover, early disorganization placed children at the greatest risk for externalizing problems (relative to other insecure categories), but was not significantly associated with internalizing problems (11, 12), suggesting that instead of having broad implications for psychopathology (21), the significance of disorganization was restricted to the externalizing domain. Consistent with conclusions from prior narrative reviews $(9,22)$, the association between insecurity and negative temperament was primarily due to resistant attachment, as neither avoidance nor disorganization was significantly associated with temperament (13).

Findings from our meta-analysis on internalizing symptomatology converged with those from a similar meta-analysis (23), but diverged from other quantitative and narrative reviews $(24,25)$. This might be because of the scope of the reviews. Our meta-analysis and one of the others (23) included only studies that assessed early attachment via observation to help rule out potential inflation of associations due to shared method variance and to evaluate a central tenet of attachment theory that early attachments have enduring significance for development (15). The other reviews $(24,25)$ included studies that used self-reports of attachment and internalizing symptoms, which might have inflated effect sizes artificially, and studies that used attachment measures administered in childhood and adolescence (i.e., 1-18 years). Thus, only one meta-analysis (23) might be considered an independent replication of ours; it corroborated evidence that early avoidant, but not resistant or disorganized, attachment is significantly associated with internalizing symptoms. 


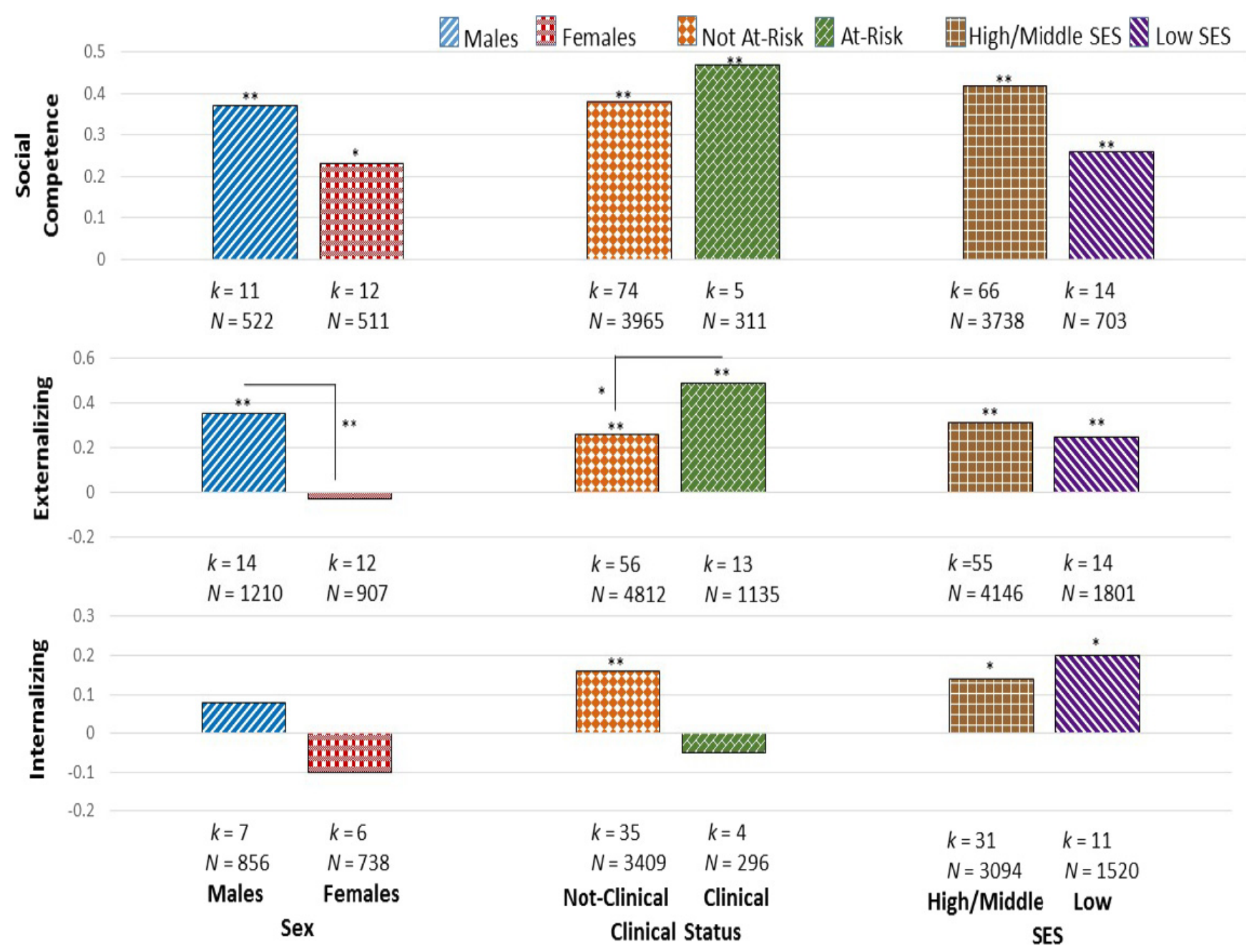

Figure 2. Combined effect sizes for secure versus insecure infants and children's peer competence, externalizing symptoms, and internalizing symptoms by children's sex, clinical status, and socioeconomic status. [Color figure can be viewed at wileyonlinelibrary.com]

Note. Top graph displays effect sizes for the association between security (vs. insecurity) and children's peer competence. Middle and bottom graphs display effect sizes for the association between insecurity (vs. security) and children's externalizing and internalizing symptoms, respectively. For each outcome domain, effect sizes for (in)security are displayed by child sex, clinical status (not clinical vs. parent/child clinical), and SES (high/middle vs. low). Positive effect sizes indicate the association was in the direction of hypotheses (e.g., security was associated meta-analytically with higher levels of social competence for girls). Negative effect sizes indicate the association was in the opposite direction of hypotheses (e.g., insecurity was associated meta-analytically with lower levels of internalizing problems for girls). Asterisks over bars indicate significant combined effect sizes. Asterisks along lines indicate significant differences between the combined effect sizes. SES $=$ socioeconomic status; $N=$ total number of children; $k=$ number of independent studies. ${ }^{*} p<.05$. ${ }^{* *} p<.01$.

\section{LOOKING AHEAD AND CONCLUSION}

Our meta-analyses, comprising the most comprehensive set of quantitative reviews of the literature on the developmental significance of early attachment, provided evidence that early attachment security is only weakly associated with infant temperament, has enduring significance for children's socioemotional (mal)adjustment, and is more strongly involved in social competence and externalizing problems than internalizing problems. Moreover, the findings underscored the across-the-board significance of all insecure attachment patterns for social competence, the broad (yet weak) significance of avoidant attachment for externalizing and internalizing symptomatology, and the relatively heightened significance of disorganized attachment for externalizing outcomes. These results are crucial for indicating not only the importance, but also the limits, of attachment for informing models of psychopathology and adjustment. In addition, even the stronger associations were modest. Our findings also challenge the claim that avoidance is important for externalizing problems, resistance for internalizing problems, and disorganization for general psychological problems $(20,21)$. Next, we suggest how researchers might address these issues.

One potential reason for the modest meta-analytic associations and partial support for the differential significance of insecure 
subtypes concerns possible limits in assessing infant attachment. Specifically, the factor structure of infant attachment as assessed by the Strange Situation (26) may be best reflected by two weakly correlated factors of attachment-related avoidance and resistance (disorganization loaded on the resistance factor, albeit not strongly; 27). In contrast to this two-factor solution, the standard coding system (including disorganized attachment and on which we based our meta-analyses) treats insecure patterns of attachment as mutually exclusive, which might have limited the ability of research to detect distinctive implications of patterns of insecurity. That said, findings from our meta-analyses did differ for resistant and disorganized attachments in two domains, which might be interpreted as inconsistent with the finding that disorganization and resistance load on a common factor. Thus, we need research on the factor structure of early attachment, especially in high-risk groups where greater variation in disorganization is typical. Similarly, we need more work comparing the predictive significance of the two-factor versus standard coding approaches for children's adaptation in the outcome domains examined here. Moreover, this work is limited by its reliance on a few scales that were not designed with psychometric modeling in mind or to capture all relevant aspects of attachment behavior. Further innovation in measuring attachment phenomena is important.

Nearly all studies on attachment and internalizing symptomatology used parent and teacher reports of symptoms. Given the less public nature of internalizing symptoms, parents and teachers might find it difficult to report on such symptoms. Research on attachment and externalizing problems also relies on such reports, and our meta-analysis revealed that studies that use parent reports $(d=.22)$ and teacher reports $(d=.30)$ produced smaller effect sizes than those that use direct observations $(d=.58 ; 11)$. Finally, despite the appreciation of developmental changes in peer relationships (e.g., increasing importance of intimacy), many studies on attachment and peer competence have not used measures sensitive to such changes; in fact, nearly half used reports of children's general social skills. Research on the implications of attachment would benefit from observational and multi-informant measures, including reports by clinicians and children, that capture variation in outcomes more successfully.

Except in the case of children's externalizing problems, our meta-analyses provided limited evidence that the impact of early (in)security was magnified when children experienced potential risk factors. Researchers might explore whether other factors increase or attenuate associations between attachment and different outcomes. Specifically, given theoretical arguments (28) and evidence (29) that the negative impact of insecurity increases when children experience many risk factors, researchers should focus on children experiencing more than one risk factor. Researchers might also consider individual factors that make children differentially susceptible to context $(30,31)$. Indeed, given our finding that insecurity was weakly associated with temperament (13), one way to reconcile the attachment and temperament literatures might be to consider whether children's negative temperamental reactivity, conceptualized as a susceptibility factor, heightens the impact of early security on outcomes - for better and for worse $(9,22)$.

Studies on the implications of attachment generally feature small samples that are underpowered to detect the meta-analytic associations reported here (median $N=44,51$, and 56 and median power for one-tailed tests $=37,30$, and $15 \%$ for studies on peer competence, externalizing, and internalizing outcomes, respectively), increasing the risk of false positives and negatives. Small, underpowered samples are particularly problematic for studies examining the significance of resistant and disorganized attachments for internalizing problems because these attachment patterns are relatively uncommon (32). Given that some of the most surprising meta-analytic findings emerged in this outcome domain, larger, well-powered investigations on attachment and internalizing symptomatology are needed. We call for multisite investigations aimed at replicating a key prediction that insecurity, generally, and resistant and disorganized attachments, specifically, heighten risk for internalizing symptomatology. A successful example of such an effort to replicate a target set of findings across many laboratories exists (33) and provides a useful model for testing this prediction. Ideally, such efforts would compare two-factor and traditional approaches to attachment, use trained observers to measure internalizing symptomatology, and examine the role of cumulative psychosocial risk and individual susceptibility factors.

Our meta-analyses provided evidence that, although modest, attachment-outcome associations do not wane over the early life course, providing support for the claim that early attachments have enduring significance for socioemotional development. Given such evidence, we need theory-driven studies that address mediating processes that account for such enduring effects. According to attachment theory, internal working models are among the mechanisms linking early attachment experiences to later outcomes $(4,5)$, and in recent years, advances have been made in our understanding of the nature of such models. Drawing on evidence from cognitive psychology that similarities across repeated experiences are summarized in the form of scripts, attachment scholars have argued that repeated secure base interactions are represented in the form of a secure base script (an understanding that when attachment problems arise, attachment figures consistently provide support in overcoming the problem; $34,35)$. Although access to a secure base script in adulthood is predicted by attachment-relevant experiences in childhood (36, 37) and associated with attachment-relevant behavior (e.g., sensitivity, 38), we need further research on the development of such knowledge in childhood and its role in explicating links between early attachment and socioemotional adjustment.

In addition to internal working models, other mechanisms have been proposed to explain associations between attachment and later outcomes, including social information processing (39), emotional reactivity and regulation (40), and continuity in 
caregiving (41). Given that attachment relationships serve as a context in which children's stress is regulated, another mechanism by which early experiences might be carried forward is via the effect of attachment on neurobiological systems involved in regulating stress. Indeed, in some studies, attachment has been linked with children's physiological responding within attachment-relevant contexts (see 42), highlighting the need for further research into potential neurobiological mechanisms. Furthermore, studies have started to cast light on novel correlates of security at the level of brain structure and function (43), which may provide clues to the mechanisms linking attachment to emotion and behavior.

Despite this wealth of theory, few studies have programmatically tested competing explanations regarding the mechanisms mediating between attachment and children's later (mal)adaptation, making it unclear whether the meta-analytic associations reported here are due to effects of attachment on the psychobiological mediators described earlier or stability in the caregiving environment. Researchers should test these possibilities by adopting many methods so neurobiological (e.g., hypothalamic-pituitary-adrenal axis function, neural activity), cognitive (e.g., internal working models, social attributions), emotional (emotion regulation), and social (e.g., continuity in care) mechanisms are examined simultaneously to tease apart their unique versus joint contribution. In conceptualizing how these multilevel mechanisms might explain attachment-outcome associations, researchers might draw on a cascade model in which associations between early attachment and competencies in subsequently developing domains of socioemotional development arise from the spreading effect of (in)security on functioning across many levels (including cognitive, emotional, and neurobiological) that may or may not depend on the ongoing quality of caregiving. Researchers could test this model through large-scale longitudinal interventions. Such studies may be important for understanding why and how attachment affects development and why, under some circumstances, it does not, information crucial for developing appropriately targeted interventions.

In summary, our meta-analyses of nearly five decades of research on early attachment relationships provide evidence consistent with claims made by attachment theory that attachment security is not determined by infants' temperamental characteristics and have long-term significance for children's socioemotional development. However, researchers need to go beyond current measurement models, place more emphasis on mediating and moderating mechanisms, and conduct joint, multisite efforts to replicate, refine, and extend core findings in attachment research.

\section{REFERENCES}

1. Bowlby, J. (1982). Attachment and loss: Vol. 1. Attachment. New York, NY: Basic Books. (Original work published 1969)
2. Ainsworth, M. D. S. (1982). Attachment: Retrospect and prospect. In C. M. Parkes \& J. Stevenson-Hinde (Eds.), The place of attachment in human behavior (pp. 3-30). New York, NY: Basic Books.

3. Sroufe, L. A. (1985). Attachment classification from the perspective of infant-caregiver relationships and infant temperament. Child Development, 56, 1-14. doi:10.2307/1130168

4. Bowlby, J. (1973). Attachment and loss: Vol. 2. Separation: Anxiety and anger. New York, NY: Basic Books.

5. Bretherton, I., \& Munholland, K. A. (2008). Internal working models in attachment relationships: Elaborating a central construct in attachment theory. In J. Cassidy \& P. R. Shaver (Eds.), Handbook of attachment: Theory, research, and clinical applications (2nd ed., pp. 102-127). New York, NY: Guilford.

6. Fearon, R. M. P., \& Belsky, J. (2016). Precursors of attachment security. In J. Cassidy \& P. R. Shaver (Eds.), Handbook of attachment: Theory, research, and clinical applications (3rd ed., pp. 291313). New York, NY: Guilford.

7. Berlin, L. J., Cassidy, J., \& Appleyard, K. (2008). The influence of early attachments on other relationships. In J. Cassidy \& P. R. Shaver (Eds.), Handbook of attachment: Theory, research, and clinical applications (2nd ed., pp. 333-347). New York, NY: Guilford.

8. DeKlyen, M., \& Greenberg, M. T. (2008). Attachment and psychopathology in childhood. In J. Cassidy \& P. R. Shaver (Eds.), Handbook of attachment: Theory, research and clinical applications (2nd ed., pp. 637-665). New York, NY: Guilford.

9. Vaughn, B. E., \& Bost, K. K. (2016). Attachment and temperament as intersecting developmental products and interacting developmental contexts throughout infancy and childhood. In J. Cassidy \& P. R. Shaver (Eds.), Handbook of attachment: Theory, research, and clinical applications (3rd ed., pp. 202-222). New York, NY: Guilford.

10. Groh, A. M., Fearon, R. P., Bakermans-Kranenburg, M. J., Van IJzendoorn, M. H., Steele, R. D., \& Roisman, G. I. (2014). The significance of attachment security for children's social competence with peers: A meta-analytic study. Attachment \& Human Development, 16, 103-136. doi:10.1080/14616734.2014.883636

11. Fearon, R. P., Bakermans-Kranenburg, M. J., Van IJzendoorn, M. H., Lapsley, A., \& Roisman, G. I. (2010). The significance of insecure attachment and disorganization in the development of children's externalizing behavior: A meta-analytic study. Child Development, 81, 435-456. doi:10.1111/j.1467-8624.2009.01405.x

12. Groh, A. M., Roisman, G. I., Van IJzendoorn, M. H., BakermansKranenburg, M. J., \& Fearon, R. (2012). The significance of insecure and disorganized attachment for children's internalizing symptoms: A meta-analytic study. Child Development, 83, 591-610. doi:10.1111/j.1467-8624.2011.01711.x

13. Groh, A. M., Narayan, A. J., Bakermans-Kranenburg, M. J., Roisman, G. I., Vaughn, B. E., Fearon, R. P., \& Van IJzendoorn, M. H. (in press). Attachment and temperament in the early life course: A meta-analytic review. Child Development. Advance online publication.

14. Belsky, J., \& Cassidy, J. (1994). Attachment theory and evidence. In M. Rutter \& D. Hay (Eds.), Development through life (pp. 373402). London, UK: Blackwell.

15. Sroufe, L. A., Egeland, B., \& Kreutzer, T. (1990). The fate of early experience following developmental change: Longitudinal approaches to individual adaptation in childhood. Child Development, 61, 1363-1373. doi:10.1111/j.1467-8624.1990.tb02867.x

16. Cohen, J. (1988). Statistical power analysis for the behavioral sciences (2nd ed.). Hillsdale, NJ: Erlbaum. 
17. McCartney, K., \& Rosenthal, R. (2000). Effect size, practical importance, and social policy for children. Child Development, 71, 173180. doi:10.1111/1467-8624.00131

18. Hoeve, M., Semon Dubas, J., Eichelsheim, V. I., Van der Laan, P. H., Smeenk, W., \& Gerris, J. R. M. (2009). The relationship between parenting and delinquency: A meta-analysis. Journal of Abnormal Child Psychology, 37, 749-775. doi:10.1007/s10802009-9310-8

19. Kawabata, Y., Alink, L. R. A., Tseng, W., Van IJzendoorn, M. H., \& Crick, N. R. (2011). Maternal and paternal parenting styles associated with relational aggression in children and adolescents: A conceptual analysis and meta-analytic review. Developmental Review, 31, 240-278. doi:10.1016/j.dr.2011.08.001

20. Sroufe, L. A. (2003). Attachment categories as reflections of multiple dimensions: Comment on Fraley and Spieker (2003). Developmental Psychology, 39, 413-416. doi:10.1037/0012-1649.39.3.413

21. Carlson, E. A. (1998). A prospective longitudinal study of attachment disorganization/disorientation. Child Development, 69, 11071128. doi:10.2307/1132365

22. Van IJzendoorn, M. H., \& Bakermans-Kranenburg, M. J. (2012). Integrating temperament and attachment. In M. Zentner \& R. L. Shiner (Eds.), Handbook of temperament (pp. 403-424). New York, NY: Guilford.

23. Madigan, S., Atkinson, L., Laurin, K., \& Benoit, D. (2013). Attachment and internalizing behavior in early childhood: A meta-analysis. Developmental Psychology, 49, 672-689. doi:10.1037/a0028793

24. Brumariu, L. E., \& Kerns, K. K. (2010). Parent-child attachment and internalizing symptoms in childhood and adolescence: A review of empirical findings and future directions. Development and Psychopathology, 22, 177-203. doi:10.1017/S0954579409990344

25. Colonnesi, C., Draijer, E. M., Stams, G. J. J. M., Van der Bruggem, C. O., Bogels, S. M., \& Noom, M. J. (2011). The relation between insecure attachment and child anxiety: A meta-analytic study. Journal of Child Clinical and Adolescent Psychology, 40, 630-645. doi:10.1080/15374416.2011.581623

26. Ainsworth, M. D. S., Blehar, M. C., Waters, E., \& Wall, S. (1978). Patterns of attachment: A psychological study of the strange situation (Vol. xviii). Hillsdale, NJ: Erlbaum.

27. Fraley, R. C., \& Spieker, S. J. (2003). Are infant attachment patterns continuously or categorically distributed? A taxometric analysis of strange situation behavior. Developmental Psychology, 39, 387-404. doi:10.1037/0012-1649.39.3.387

28. Rutter, M. (1979). Protective factors in children's responses to stress and disadvantage. In M. W. Kent \& J. E. Rolf (Eds.), Primary prevention in psychopathology: Social competence in children (pp. 4974). Hanover, NH: University Press of New England.

29. Belsky, J., \& Fearon, R. (2002). Infant-mother attachment security, contextual risk, and early development: A moderational analysis. Development and Psychopathology, 14, 293-310. doi:10.1017/ S0954579402002067

30. Belsky, J. (1997). Theory testing, effect-size evaluation, and differential susceptibility to rearing influence: The case of mothering and attachment. Child Development, 64, 598-600. doi:10.2307/1132110

31. Ellis, B. J., Boyce, W. T., Belsky, J., Bakermans-Kranenburg, M. J., \& Van IJzendoorn, M. H. (2011). Differential susceptibility to the environment: An evolutionary-neurodevelopmental theory.
Development and Psychopathology, 23, 7-28. doi:10.1017/ S0954579410000611

32. Mesman, J., Van IJzendoorn, M. H., \& Sagi-Schwartz, A. (2016). Cross-cultural patterns of attachment: Universal and contextual dimensions. In J. Cassidy \& P. R. Shaver (Eds.), Handbook of attachment: Theory, research, and clinical applications (3rd ed., pp. 852-877). New York, NY: Guilford.

33. Klein, R. A., Ratliff, K. A., Vianello, M., Adams, R. B., Jr., Bahník, Š., Bernstein, M. J., ... Nosek, B. A. (2014). Investigating variation in replicability: A "many labs" replication project. Social Psychology, 45, 142-152. doi:10.1027/1864-9335/a000178

34. Bretherton, I. (1987). New perspectives on attachment relations: Security, communication, and working models. In J. Osofsky (Ed.), Handbook of infant development (2nd ed., pp. 1061-1100). New York, NY: Wiley.

35. Waters, H. S., \& Waters, E. (2006). The attachment working model concept: Among other things, we build script-like representations of secure base experiences. Attachment \& Human Development, 8, 185-197. doi:10.1080/14616730600856016

36. Steele, R. D., Waters, T. E. A., Bost, K. K., Vaughn, B. E., Truitt, W., Waters, H. S., ... Roisman, G. I. (2014). Caregiving antecedents of secure base script knowledge: A comparative analysis of young adult attachment representations. Developmental Psychology, 50, 2526-2538. doi:10.1037/a0037992

37. Schoenmaker, C., Juffer, F., Van IJzendoorn, M. H., Linting, M., Van der Voort, A., \& Bakermans-Kranenburg, M. J. (2015). From maternal sensitivity in infancy to adult attachment representations: A longitudinal adoption study with secure base scripts. Attachment \& Human Development, 17, 241-256. doi:10.1080/ 14616734.2015.1037315

38. Coppola, G., Vaughn, B. E., Cassibba, R., \& Costantini, A. (2006). The attachment script representation procedure in an Italian sample: Associations with Adult Attachment Interview scales and with maternal sensitivity. Attachment \& Human Development, 8, 209219. doi:10.1080/14616730600856065

39. Dykas, M. J., \& Cassidy, J. (2011). Attachment and the processing of social information across the life span: Theory and evidence. Psychological Bulletin, 137, 19-46. doi:10.1037/a0021367

40. Cassidy, J. (1994). Emotion regulation: Influences of attachment relationships. Monographs of the Society for Research in Child Development, 59(Serial No. 2/3), 228-249. doi:10.1111/j.15405834.1994.tb01287.x

41. Lamb, M. E., Thompson, R. A., Gardner, W. P., Charnov, E. L., \& Estes, D. (1984). Security of infantile attachment as assessed in the strange situation: Its study and biological interpretation. Behavioral and Brain Sciences, 7, 127-171. doi:10.1017/S0140525X00026522

42. Fearon, R. P., Groh, A. M., Bakermans-Kranenburg, M. J., Van IJzendoorn, M. H., \& Roisman, G. I. (2016). Attachment and development psychopathology. In D. Cicchetti (Ed.), Developmental psychopathology, volume one, theory and method (3rd ed., pp. 325384). New York, NY: Wiley.

43. Coan, J. A. (2016). Towards a neuroscience of attachment. In J. Cassidy \& P. R. Shaver (Eds.), Handbook of attachment: Theory, research, and clinical applications (3rd ed., pp. 242-269). New York, NY: Guilford. 